\title{
Día del Dentista, según la cosmovisión maya.
}

\author{
Day of the dentist, according to the Mayan cosmovision. \\ Eduardo Ensaldo-Fuentes,* Eduardo Ensaldo-Carrasco, ${ }^{\ddagger}$ Ricardo Rivas-Muñoz*
}

\section{RESUMEN}

El día del odontólogo tradicionalmente se festeja el 9 de febrero, en conmemoración a Santa Apolonia, quien el 9 de febrero del año 248 d.C., por no renunciar a su fe cristiana, es martirizada quitándole los dientes. Sin embargo, existe una historia de origen maya, escrita en el Popol Vuh, la de Vucub Caquix, ave mítica antropomorfa, a quien se le extraen los dientes. Este hecho acontece antes de la creación del mundo, el 13 de agosto del año 3114 a.C. Este hallazgo surge al relacionar el Popol Vuh con las imágenes representadas en la vasija maya K 1226, la estela 25 de Izapa y las inscripciones de la estela de Cobá, Quintana Roo. Por lo anterior, proponemos que este acontecimiento podría tomarse en cuenta para conmemorar en México el día del dentista el 13 de agosto, puesto que ello sería una forma de revalorar y reafirmar nuestra identidad prehispánica.

Palabras clave: Dentista, dientes, Apolonia, Vucub Caquix, Popol Vuh, árbol, vía láctea, vasija, estela.

\section{ABSTRACT}

The dentist's day is traditionally celebrated on February 9, in commemoration of Santa Apolonia, who on February 9 of the year $248 A D$, for not giving up her Christian faith, is martyred by taking her teeth. However, there is a story of Mayan origin, written in Popol Vuh, that of Vucub Caquix, a mythical anthropomorphic bird, whose teeth are extracted. This fact occurs before the creation of the world, on August 13, 3114 BC. This finding arises when the Popol Vuh is related to the images represented in the Mayan vessel K 1226, stela 25 of Izapa and the inscriptions of the stela de Cobá, Quintana Roo. Therefore, we propose that this event could be taken into account to commemorate August 13, as the day of the dentist, as a way to revalue and reaffirm our pre-Hispanic identity.

Keywords: Dentist, teeth, Apollonia, Vucub Caquix, Popol Vuh, tree, milky way, vessel, stele.

\section{INTRODUCCIÓN}

$\mathrm{L}$ a conmemoración del Día Nacional del Odontólogo, $\downarrow$ tradicionalmente se festeja el 9 de febrero, ${ }^{1}$ que de acuerdo con el calendario es el día de Santa Apolonia. Esta herencia conmemorativa proviene, como consecuencia histórica, de la conquista de México por los españoles, comandados por Hernán Cortés, mismos que impusieron la religión cristiana.

A pesar de los intentos del exterminio de las creencias culturales de los antiguos pobladores de México por parte de los conquistadores, muchas de éstas prevalecieron. Una de las fuentes documentales más importantes y reveladoras de la cosmovisión prehispánica maya es el

\footnotetext{
* Facultad de Estudios Superiores Iztacala de la Universidad Nacional Autónoma de México. Tlalnepantla de Baz, México.

‡ Comisión Nacional de Arbitraje Médico, México. Universidad de Edimburgo, UK.

Recibido: 16 Diciembre 2019.

Aceptado para publicación: 18 Diciembre 2019.
}

Popol Vuh, en el cual se relata la historia de la extracción múltiple de dientes realizada por un anciano a Vucub Caquix, un ave vanidosa que se jactaba de su belleza. ${ }^{2}$ Linda Schele al hacer un estudio comparativo e interpretación de diversos hallazgos arqueológicos, establece la fecha, de las antes mencionadas extracciones dentales: 13 de agosto de 3114 a.C. ${ }^{3}$

Al revalorar la riqueza de nuestro reservorio cultural prehispánico, proponemos integrar el día 13 de agosto para la celebración del Día del Odontólogo como una forma de homenajear y afirmar nuestra identidad mexicana.

Por otro lado, el patrono maya de los dentistas, según el contexto maya, es la dualidad primigenia mencionada en el Popol Vuh, la cual se manifiesta en diferentes escenarios, con distintos nombres, Tepeu y Gucumatz, los formadores. ${ }^{4}$

\section{ANTECEDENTES}

Santa Apolonia es, en el santoral cristiano, considerada como la patrona de los dentistas. Esta tradición se basa en 
que en la ciudad de Alejandría (Egipto), el 9 de febrero del año 248 d.C., Apolonia fue martirizada por negarse a renunciar a su fe cristiana y sus dientes le fueron fracturados y extirpados. Lo sobresaliente de esta historia es que, antes de morir en la hoguera, se ofreció a interceder ante Dios por aquéllos que sufrieran dolores dentales. ${ }^{5}$ Por lo que Santa Apolonia podría considerarse, más bien, como la Santa Patrona de los pacientes, es decir, aquéllos que sufren dolores dentales. Esto se aprecia en el siguiente rezo a Santa Apolonia:

«Bendita Santa Apolonia, que por tu virginidad y martirio mereciste del Señor ser instituida abogada contra el dolor de muelas y dientes. Te suplicamos fervorosos interceda con el Dios de las misericordias para que esta criatura (nombre del doliente) sea sanada. Señor: accede benigno a la súplica que te dirigimos. Amén (Después se rezará un Padre Nuestro a Santa Apolonia y tres a la Santísima Trinidad)..16

En este rezo se le pide a Santa Apolonia que abogue, ante el Señor, por el martirio de los que padecen el «dolor de muelas y dientes»; en tal caso sería la Santa Patrona de los dolientes y no de los dentistas. Entonces, ipor qué se le considera a Santa Apolonia como la patrona de los dentistas y no de los pacientes? Quizá un motivo probable de la canonización de Apolonia radique históricamente en el intento de eliminar el culto pagano de adoración a Apolo, dios de la medicina. Esto fue identificado por Salvador Lerman (1974) al señalar que «(...) posiblemente el hecho de que la historia de Santa Apolonia no sea más que una forma de culto de Apolo entre los cristianos que no pudiendo adorar al Sol para calmar sus dolores dentarios, por ser un Dios pagano, crearon una Santa con su nombre (Apolo-nia) en una Virgen cristiana martirizada en el siglo III d. De J.C, (año 248) en Alejandría, bajo el reinado de Filipo el Árabe. ${ }^{7}$

Independiente de las razones que sugiere Salvador Lerman, también podríamos interpretar que el odontólogo es «un Instrumento Divino, por medio del cual se realiza la voluntad del Señor, para aquellos creyentes que invoquen a Santa Apolonia.»

En el México antiguo existe un mito maya prehispánico que relata un acto quirúrgico consistente en múltiples extracciones dentales, realizadas a Vucub Caquix (siete guacamayo). ${ }^{2}$ Las extracciones dentales fueron efectuadas por quien podría ser considerado «El Patrono de los Dentistas».

El probable Patrono maya de los dentistas es la dualidad primigenia Tepeu y Gucumatz, mencionada en el Popol Vuh, la cual se manifiesta en diferentes escenarios, con distintos nombres, el nombre que tiene el anciano,

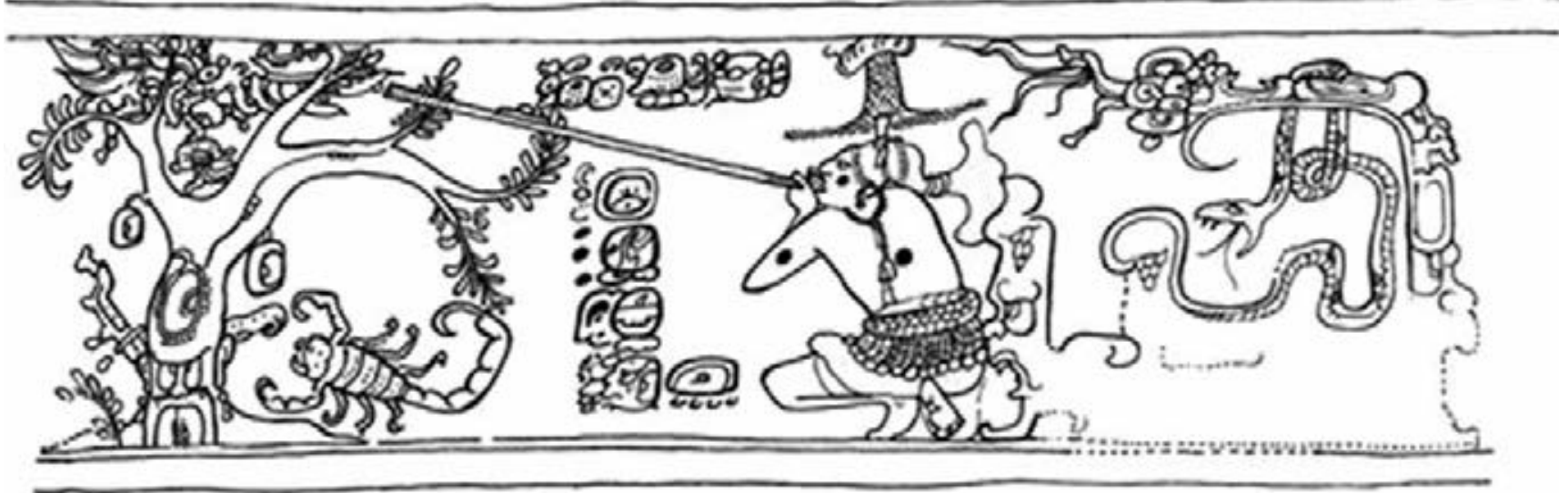

Figura 1: Hunahpú con un tiro de cerbatana, le provoca el dolor de dientes y mandíbula a Vucub Caquix. Dibujo de: Linda Schele, http://research.famsi.org/schele.html

Linda Schele (2001) investiga e identifica al ave Itzam-Yeh (prototipo del periodo clásico de Vucub Caquix), al cerbatanero que es Hunahpú y al escorpión que se encuentra al pie del árbol, que sorprendentemente representa y coincide en nombre y ubicación con la constelación de escorpión, de la cosmogonía actual, a diferencia de sagitario, que es la constelación que prosigue y que para los mayas era la serpiente de cascabel, misma que en esta vasija se aprecia colgada de una rama del árbol. Por otro lado, Dennis Tedlock ${ }^{8}$ menciona que Miguel Alvarado López, su informante maya, le comunicó que el Siete Guacamayo son, en igual número, las siete estrellas de la osa mayor (Tedlock, 1993: 341); todo lo anterior confirma que el mito es escenificado en la bóveda celeste, por las estrellas, como lo corrobora la interpretación de los glifos que se encuentran delante del cerbatanero, en esta misma vasija, en la que se lee: «Entró en el cielo Itzam-Yeh». 


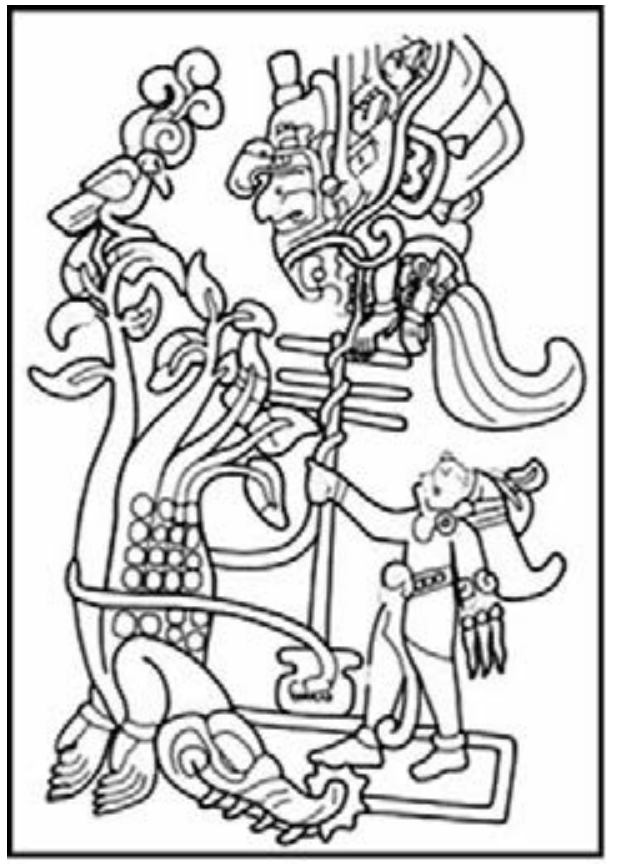

Figura 2: Estela 25 de Izapa. Dibujo de: Oswaldo Chinchilla Mazariegos.

en este mito, es (en lengua maya quiche) Saqi Nim Aq, Gran Jabalí Blanco, y Saqi Nima Tziz, Gran Pizote Blanco (coatí de nariz blanca). ${ }^{9}$

Narra el Popol Vuh ${ }^{2}$ que Vucub Caquix (siete guacamayo) era una ave antropomorfa, que se creía Dios (¿lucifer bíblico?), muy arrogante, vanidoso y orgulloso de sus atributos físicos, ya que poseía una enorme belleza; sus ojos eran de metales preciosos que brillaban como el sol, su nariz blanca y resplandeciente como la luna y sus dientes, llenos de piedras preciosas, eran majestuosos como la faz del cielo, todo esto le daba la sensación de ser la culminación de la creación, por lo que se declaró ser el sol, la luna y clamaba para que todos lo adorasen. Dos muchachos gemelos, Hunahpú e Ixbalanqué, dijeron: «No está bien que esto sea así delante del Corazón del Cielo, acabemos con él y sus riquezas, sus piedras verdes, sus metales preciosos, sus esmeraldas, de que se enorgullece, porque no debe envanecerse por el poder ni por la riqueza. Y además todavía no se habían creado ni el sol ni la luna».

Los hermanos gemelos se dirigieron entonces al árbol de Nance, el alimento preferido del pajarraco, donde acostumbraba comer; le esperaron y al verlo entre las ramas Hunahpú le disparó con su cerbatana y le dio en la quijada, Vucub Caquix cayó desde lo alto del árbol, trataron de apresarlo, pero en la lucha el ave le arrancó un brazo a Hunahpú y huyó.

Los hermanos gemelos, entonces, buscaron la ayuda de su abuelo diciéndole: «Acompañadnos, para recoger mi brazo y decid que somos vuestros nietos huérfanos, con los que compartes el pan que ganas, curando los ojos, poniendo los huesos en su lugar y quitando los gusanos de los dientes»; al acercarse a la casa de Vucub Caquix éste le preguntó al anciano: «įué es lo que les trae por aquí?»; el abuelo respondió lo convenido y Vucub Caquix le suplicó que lo curara, pues padecía dolores en todos los dientes, ya que dos demonios le hirieron en la mandíbula. El anciano después de examinarlo le respondió: «La causa de tu dolor es debido a que tus dientes están llenos de gusanos, así que hay

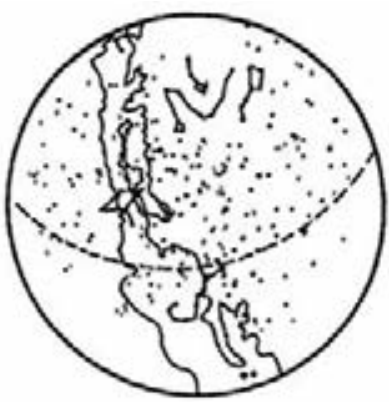

Sunset at 6:38 pm

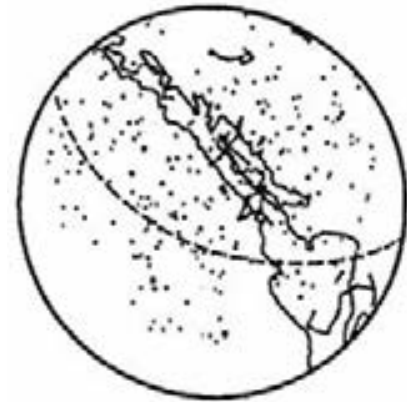

10:38 pm: Itzam-Yeh knocked out of the crocodile tree, readying the sky for creation

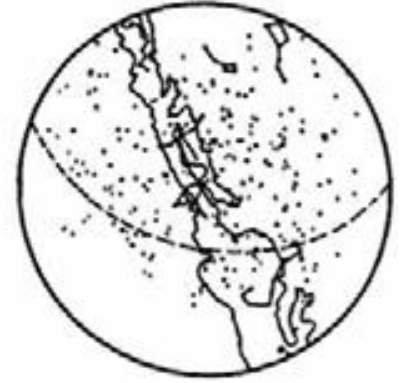

8:38 pm: the crocodile tree turns as

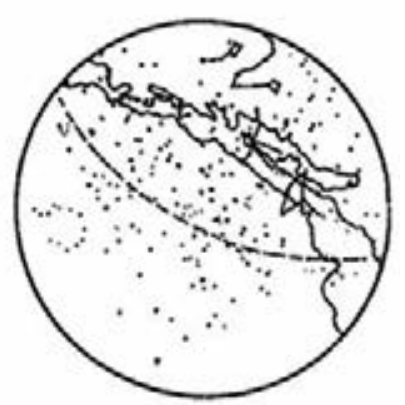

$12: 38$ am: the crocodile tree transforms into the cosmic monster Itzam-Yeh dives toward the horizon

Figura 3: Al ocultarse el sol, el 13 de agosto (6.38 pm), se observa a la osa mayor (Vucub Caquix), «entrando al cielo» queriéndose apropiar del árbol de «el mundo de arrogancia», es repelido por un tiro de cerbatana $(8.38 \mathrm{pm})$, y finalmente le son extraídos sus dientes y muere (10:38 pm), hecho que se comprueba al desaparecer la osa mayor de la bóveda celeste. Dibujos de: Linda Schele. 
que sacarlos». Vucub Caquix en ese momento emitió el sentido y el valor de lo que representan los dientes en la cultura maya y le dijo al anciano: «Mis dientes son mi sustento y poder, por ellos soy Señor, no está bien que los pierda». El anciano le respondió: «No te preocupes, en su lugar te implantaré unos dientes de hueso; forzado por el dolor Vucub Caquix aceptó el tratamiento y una vez despojado de sus dientes vio cómo perdió su señorío, al momento el anciano le implantó dientes de masa de maíz en la mandíbula y antes de morir le fueron arrancados también sus metales preciosos. Finalmente le colocó el brazo a Hunahpú. ${ }^{2}$

Después de leer esta historia emprendimos la búsqueda específica de la imagen que correspondiera a una extracción dental realizada a un guacamayo por un anciano, así que recurrimos a la iconografía maya. Nuestra búsqueda no tuvo el resultado esperado, pero más sorprendente es lo que expondremos a continuación: nos encontramos con dos imágenes, una corresponde a la vasija maya estilo códice K1226 del periodo clásico, propiedad del Museo de Arte Fino en Boston, Massachusetts, en la cual se aprecia a un cazador en cuclillas, sosteniendo una cerbatana con ambas manos y apuntando hacia un árbol en el que se aprecia un ave cayendo de cabeza (Figura 1).

Para los mayas el concepto de cielo era un túnel que se extendía desde el eje polar norte hasta escorpión en el sur; al transpolar esta posición guiada por mapas estelares a la imagen de la vasija (Figura 1), Linda Schele (Schele 2001: 74) ${ }^{10}$ propone que el árbol (Wakah-Chan), donde se posa el ave, es simbólicamente la vía láctea que se levanta de sur a norte y que se manifiesta con plenitud el 13 de agosto, con escorpión en el extremo sur, en forma similar a la imagen de la vasija antes mencionada.

La segunda imagen representativa de este mito mayaquiché se encuentra en la estela número 25 de Izapa (Figura 2), en la cual vemos un cocodrilo extendido de forma vertical (como si estuviera colgando de su cola y con sus fauces apuntando al piso), sus patas delanteras representan las raíces de un árbol, su dorso escamoso constituye el tronco del árbol, el cual se ramifica hacia arriba, las patas traseras y su cola ahora son ramas, es un árbol cocodrilo; es otra imagen representativa del Wakah-Chan o vía láctea, en cuya rama, la más alta del árbol, lado izquierdo del lector, se posa un ave celeste con majestuoso tocado que está mirando de frente a Vucub Caquix, lado derecho del lector, el cual es identificado por sus características alas serpentinas, plumas, cola, pico ${ }^{8}$ y sosteniendo un brazo humano en su vientre; esta ave se encuentra amarrada (cautiva) por una serpiente que le circunda el cuerpo y que baja enredándose en un poste o báculo, el cual es sostenido por Hunahpú, que está al pie del mismo, sin su brazo izquierdo y en su lugar se aprecian gotas de sangre (símbolo trifoliado).

Para verificar el significado simbólico de ambas imágenes, Linda Schele (2001, p 55-119.) ${ }^{10}$ también las relacionó con los huesos labrados, con escenas de canoa, encontrados en el entierro 116 de Tikal, Guatemala y buscó la posición de la constelación de escorpión y de la osa mayor en la fecha del 13 de agosto del año 690 d.C., fecha correspondiente a 4 Ahau, 8 Kumk'u vinculada al día de la creación inscrita, en el Tablero de La Cruz, Palenque, Chiapas y la estela 1 de Cobá, Quintana Roo. El resultado que obtuvo lo verificó en dos planetarios diferentes, el Planetario Hayden del American Museum of Natural History, New York y el Planetario Hansen de Salt Lake, Utah, cuyo resultado expongo a continuación:

«Al oscurecerse el cielo el 13 de agosto (6:38 pm), se observa a la osa mayor (Vucub Caquix), 'entrando al cielo' queriéndose apropiar del árbol del mundo o vía láctea, ante su pretensión y arrogancia es repelido por un tiro de cerbatana (8:38 pm), y finalmente le son extraídos sus dientes y muere (10:38 pm), hecho que se comprueba al desaparecer la osa mayor de la bóveda celeste (Figura 3), posteriormente el árbol cocodrilo se transforma en canoa cocodrilo que lleva al Dios del maíz, Hu Nal Ye, para que realice la creación del mundo el 13 de agosto de 3114 a.C., según lo inscrito en la estela 1 de Cobá, Quintana Roo.»

\section{CONCLUSIONES}

En el contexto prehispánico maya, el 13 de agosto de 3114 a.C. es cuando se realiza la creación, no sin antes extraerle los dientes a Vucub Caquix; este acto simbólico es observable en la bóveda celeste y se sigue repitiendo cada año hasta nuestra era. Por todo lo antes mencionado, la propuesta es: festejar en México el Día del Odontólogo el 13 de agosto.

En relación al nombre del patrono del dentista maya, Nahum Megged (1991), se refiere al simbolismo de la dualidad primigenia mencionada en el Popol Vuh, la cual se manifiesta en diferentes escenarios, con diferentes nombres, de la siguiente forma:

«(...) así fue creado por Tepeu y Gucumatz, los formadores, que se transforman en la figura de Ixpiyacoc e Ixmucané, que en el contexto cosmogónico maya, son los creadores, los ancianos y adivinos.... «Estos abuelos de los gemelos son seres centrales en la teogonía local (dos fases solares) y acompañan desde un principio al corazón del cielo, siendo el equivalente masculino y femenino de 
la pareja masculina de progenitores (creador y formador). Esta pareja de abuelos divinos, es la que relaciona a la teogonía del libro básico con las andanzas de los gemelos».

De acuerdo con la cita anterior el nombre del patrono de los dentistas, según el contexto maya es TepeuGucumatz.

\section{BIBLIOGRAFÍA}

1. Cámara de Diputados. H. Congreso de la Unión. LXIII Legislatura. "Día Nacional del Odontólogo" Boletín №. 3391, 10 de abril de 2014.

2. Recinos A. Popol Vuh. México: Fondo de Cultura Económica; 2003. pp. 33-39.

3. Freidel D, Schele L, Parker J. El cosmos maya. México: Fondo de Cultura Económica; 2001.

4. Megged N. El Universo del Popol Vuh. México: Editorial Diana; 1991. p. 43.
5. Rivas R. Santa Apolonia. Disponible en: https://www.iztacala.unam. $\mathrm{mx} /$ rrivas/lecturas/historia/santa_apolonia/stapolonia.html

6. Papa León Magno. Enchiridión Leonis Papae (1740). México: Editorial Roca; 1976. p. 89. En: Sanfilippo BJ. La leyenda de Santa Apolonia y el día del Dentista. Editada por la Asociación Dental del Distrito Federal. México: 1990. p. 14.

7. Lerman S. Historia de la odontología y sus ejercicio legal. Argentina: Editorial Mundi; 1974. p. 27.

8. Tedlock D. Popol Vuh. México: Diana; 1993. p. 149

9. Craveri M. Popol Vuh Herramienta para una lectura crítica del texto K'iche'. México: Universidad Nacional Autónoma de México; 2013. p. 28.

10. Schele L, Wanyerka P. The proceedings of the Maya hieroglyphic Workshop. Volumes 2001-2004. U.Texas: P. Wanyerka; 2001. Digit. 2011.

Correspondencia:

\section{Ricardo Rivas Muñoz}

E-mail: rivasmr@prodigy.net.mx 